Research Article

\title{
Study on the Geo-Stress Loading and Excavation Unloading Devices of the Large-Scale Photoelastic Model Test for Deep-Buried Tunnels
}

\author{
Jiaqi Guo $\left(10,{ }^{1}\right.$ Binzhong Zhu, ${ }^{1}$ Xiliang Liu $(1),{ }^{1}$ Jing Luo, ${ }^{2}$ and Zhaoyuan $\mathrm{Li}^{2}$ \\ ${ }^{1}$ School of Civil Engineering, Henan Polytechnic University, Jiaozuo, Henan 454003, China \\ ${ }^{2}$ School of Mechanical and Power Engineering, Henan Polytechnic University, Jiaozuo, Henan 454003, China \\ Correspondence should be addressed to Xiliang Liu; xlliuhpu@163.com
}

Received 24 July 2021; Accepted 16 August 2021; Published 31 August 2021

Academic Editor: Gan Feng

Copyright (c) 2021 Jiaqi Guo et al. This is an open access article distributed under the Creative Commons Attribution License, which permits unrestricted use, distribution, and reproduction in any medium, provided the original work is properly cited.

\begin{abstract}
At present, theoretical analysis, numerical simulation, and other methods cannot be used to properly solve the problems associated with the stability and bearing capacity of the surrounding rock and its supporting system, the interaction between the supporting structure and surrounding rock, and the sharing role of each supporting structure, all of which commonly occur in deep tunnels. The model test method represented by the photoelastic test is still an important approach to study this kind of problem. In view of the deficiency of the current loading system of the photoelastic model test, we developed a geo-stress loading system for the photoelastic model test, which can simulate the in situ geo-stress environment of unidirectional loading, bidirectional equal pressure, bidirectional unequal pressure, and tridirectional unequal pressure. The universal retaining force loading rod can realize the stability and effective compensation of loading, which is an original design. According to the principle of umbrella-shaped expansion and contraction mechanism, an excavation unloading device for the photoelastic model test is developed, which can realize the simulation of various degrees of displacement release in the excavation process of deep tunnels and other underground projects. The loading simulation test and excavation unloading simulation test show that the geo-stress loading system and excavation unloading device developed in this paper are flexible, exhibit good performance, and can fully achieve their respective test functions. The combination of two devices can compensate for the insufficiency of the current photoelastic model test and will promote the application of photoelastic model tests in underground engineering applications such as deep tunnel projects.
\end{abstract}

\section{Introduction}

Deep tunnels are mechanical bodies with complex properties, stress states, and boundary conditions. Researchers at home and abroad have conducted many in-depth studies on the distribution of the stress field and displacement field of tunnel surrounding rock and the supporting structure under different construction methods and supporting types based on theoretical analyses, numerical calculations, and model tests [1-5].Specifically, based on the theoretical analysis method of mathematical mechanics, only the analytical solutions for the stress and displacement field of the tunnel surrounding rock mass with a simple section and under simple support conditions can be obtained [6-8]. The numerical analysis method [9-11] based on the finite element, finite difference, and discrete element methods provides a powerful tool for the stress analysis of tunnel engineering with complex crosssections and composite supports. However, the selection of the constitutive model and parameters requires substantial engineering experience and calculation abilities. Similar model tests have unique advantages in terms of solving mechanical problems that are difficult to be described by mathematical analysis methods in deep tunnel engineering applications and verifying the correctness of numerical simulation results [12-14]. However, in the traditional geomechanical model test, due to the limited number of monitoring points and the interference caused by the embedded monitoring instruments, it is difficult to obtain enough mechanical information for the surrounding rock mass and supporting structure with high quality, and it is difficult to 
recycle the similar materials. Photoelastic model tests have the advantages of convenience when constructing models, high sensitivity, and low cost. All the field information of a research object can be directly observed. Therefore, it is still an ideal method for studying the stress distribution and concentration state of the surrounding rock mass and supporting structure of deep tunnels.

The photoelastic model test combines optical theory and elastic theory. A photoelastic material is used to construct a model that is similar in shape and size to that of the experimental prototype according to similarity theory. The change in the optical properties of the model under a load similar to that of the prototype tunnel is measured in the polarized field to analyse the stress distribution of the research object $[15,16]$. Deep tunnels and other research objects are always in a certain in situ geo-stress field. When using the photoelastic model test method to perform the corresponding research, it is very important to apply the boundary load, which is similar to the actual force of the prototype tunnel. There are many loading methods in photoelastic model tests, such as weight loading [17-19], air pressure loading [20, 21], mechanical loading [22, 23], and electrohydraulic servo loading $[24,25]$. These methods generally require matching testing equipment and facilities to complete the loading process. Specifically, weight loading is mainly realized by using a lever system, which has the characteristics of a stable load value and no influence on the free deformation of the structure, but generally, the load level is small, and only unidirectional loading can be applied. It is not consistent with the actual in situ geo-stress situation and is thus unsuitable. Air pressure loading can reflect the loading value through the pressure gauge, and the loading and unloading process is convenient, especially for a uniform load, but a compressed air pump is required to have good control over the performance. Mechanical loading can be realized by using screw jacks and springs, and a force sensor is needed to measure the loading value. The equipment is simple and easy to use. However, when the structure is deformed during the loading process, it may lead to automatic unloading. A timely adjustment is required to keep the load unchanged. Electrohydraulic servo loading is the most commonly used loading method in the model test and has many advantages. However, this loading method has problems associated with complex system pipelines, expensive equipment, and oil leakage that interferes with test observations, and its stability in photoelastic test bench also requires special attention.

The excavation of underground engineering projects, such as tunnelling, destroys the original equilibrium state of the surrounding rock mass and causes the stress of the surrounding rock mass to be redistributed until it reaches a new equilibrium state. An important feature of the stress redistribution of the surrounding rock mass is that the radial stress gradually decreases from the inside of the surrounding rock mass to the excavation profile and becomes zero at the excavation profile. Due to the viscoelastic and plastic mechanical properties of a deep-buried rock mass, the stress adjustment process caused by the instantaneous excavation of a rock mass is time-dependent. The displacement of the excavation profile will gradually decrease and reach a stable state after a certain period of time; in the process of displacement and stress adjustment, the supporting structure will gradually be utilized. To study the stress characteristics and dynamic evolution law of the surrounding rock mass and support system in the process of tunnel excavation, the excavation unloading device can be set in the photoelastic model test of a deep tunnel, and the tunnel excavation effect and subsequent adjustment process can be studied by controlling the excavation unloading process. To date, there is no published report that studies the photoelastic model test considering the release effect of excavation unloading. In geomechanical model test research, the simulation of the excavation release process is mainly realized by air bag decompression [26] and simulated excavation [27]. Among them, the model of the excavation process of air bag decompression is quite different from the actual process, and the excavation response effect of the surrounding rock mass and supporting structure can only be reflected to a certain extent, while the latter exhibits better performance, but it is difficult to be implemented in photoelastic model tests.

At present, the geo-stress loading devices of photoelastic model tests are mostly under the condition of unidirectional loading or simple bidirectional loading (bidirectional isobaric or $K_{0}$ state). However, when actual tunnel engineering projects are simplified to a plane strain model, most of the projects are in a bidirectional unequal geo-stress state. A small number of bidirectional unequal pressure geo-stress loading devices, which are improved on the above loading system and used for photoelastic model tests, has many problems, such as lack of control, poor stability, and high cost. As a result of the lack of an excavation unloading device to simulate the tunnel excavation effect, the photoelastic model test is unable to capture the stress characteristics and transmission mechanism of the surrounding rock mass and supporting structure in the process of displacement adjustment after tunnel excavation. Therefore, to meet actual requirements, we developed a geo-stress loading system for the photoelastic model test based on the principle of lead screw loading, which can realize unidirectional loading, bidirectional equal loading, and bidirectional unequal pressure loading. In addition, on the basis of the umbrellashaped expansion and contraction mechanism, we developed an excavation unloading device for the excavation profile in photoelastic model tests and carried out some simulation tests to verify these above devices for the photoelastic model test. The geo-stress loading and excavation unloading devices of the photoelastic test developed in this paper can improve the research method of the photoelastic model test and are of great significance to study the stress characteristics, force transmission process, and sharing mechanism of the surrounding rock mass and supporting structure considering the excavation effect in a real stress state.

\section{Geo-Stress Loading Device for a Large-Scale Photoelastic Model Test}

The geo-stress loading device for the photoelastic model should meet the following requirements: the magnitude and direction of the applied load should be accurate, and it 
should be stable and reliable throughout the entire test process with a simple structure, clear force transmission path, easy installation, and convenient observation. The existing loading frame of the PA-420 photoelastometer provides a weight-lever loading mode, which can realize compression, tension, and bending tests of small-scale photoelastic models; the loading frame can only realize the point or line load, which is vertical unidirectional, of small photoelastic model, but the loading frame has difficulty in meeting the loading requirements for large-scale photoelastic models. To simulate the high stress boundary conditions of tunnels in deep-buried environments, it is necessary to design a geo-stress loading device and related matching mechanism to meet the stress boundary conditions required by large-scale photoelastic model tests.

2.1. Comparative Analysis of the Geo-Stress Loading Modes for the Photoelastic Model Test. According to the common loading mode of the universal loading frame, the lever loading scheme and lead screw loading scheme are compared and analysed, as shown in Figure 1. Specifically, lever loading uses two levers arranged horizontally and vertically to simultaneously act on the photoelastic model through the loading parts, while the lead screw loading is driven by rotating the hand-wheel nut to push the loading part to apply horizontal and vertical loads on the photoelastic model. During the photoelastic test, it is necessary to release the displacement on the boundary of the tunnel profile in the middle of the photoelastic model. For the lead screw loading method, the preload of the thread is difficult to be kept constant during the excavation unloading process, and the applied boundary load will change, while the lever loading method has the obvious advantage of maintaining a constant load.

To further analyse the feasibility of the lever loading scheme, Creo software is used to conduct a three-dimensional model of the lever loading device, as shown in Figure 2. The lever loading device is composed of an internal reaction frame and an external frame; the internal reaction frame is welded as a whole by square steel, and the external frame is connected to flat steel with rectangular steel tube bolts. The internal reaction frame can move up and down within the external frame by using the lead screw lifting mechanism, and the external frame can move left and right on the guide rail of the device pedestal to ensure the fringe observation of the full light field of the photoelastic model under the condition of limited movement.

Two sets of horizontal and vertical loading levers are set on the internal frame. The lever in the horizontal direction is the vertical force loading lever, and the weight is suspended at the end of the lever to apply the vertical load. The lever in the vertical direction is the horizontal force loading lever. The end of the lever is connected to the steel wire rope, and the horizontal load is applied by changing the gravity direction through the pulley. The loading part can act on the two side surfaces of the photoelastic model, and the load in the other two directions is realized by the support force of the internal reaction frame. The self-weight of the vertical force loading lever in the horizontal direction is offset by the balance weight set at one end of the nonsuspended weight.

After completing the design of the geo-stress loading device for the lever loading mode, its performance was predicted and analysed. The following deficiencies associated with the lever loading mode was found: (1) Generally, the lever loading mode changes the load on the photoelastic model by increasing and decreasing the weights, so it is difficult to realize stepless continuous loading; in actual practice, iron powder or water with high density can be used to realize stepless loading instead of weights, but the test operation is very complicated. (2) When loading, the lever will rotate due to the deformation of the model, which will cause a slight inclination of the axis of the concentrated load, resulting in an inaccurate size and direction of the load. (3) There is a damping effect at the fulcrum and hinge of the lever; the larger the load is, the more obvious the damping, which affects the loading accuracy. (4) Due to the deformation of the loading part itself, it is difficult to uniformly transfer the concentrated force to the loading surface. (5) The lever loading forces in the two directions affect each other, and the photoelastic model is affected by the friction on the support reaction frame, which causes the boundary stress conditions on both sides of the model to be inconsistent in the horizontal direction. The above problems are difficult to be solved by using simple mechanical processes. Therefore, with further research and analysis, we abandon the lever loading scheme and return to a design idea based on the lead screw loading scheme.

\subsection{Components and Working Mechanism of the Geo-Stress} Loading Device for the Photoelastic Test. The geo-stress device of the photoelastic test is composed of a pedestal, reaction frame, worm screw jack, force sensor, loading mechanism for the universal retaining force, loading plate for load sharing, and bottom support plate, as shown in Figure 3.

The middle space of the geo-stress loading device is used to place the photoelastic model plate. A set of worm screw jacks is arranged above the reaction frame and on the left and right sides to manually apply the required boundary load. The load is transmitted to the loading mechanism for the universal retaining force through the connected force sensor and then uniformly transmitted to the photoelastic model plate through the load sharing plate. The force sensor can directly output the load value. The loading mechanism for the universal retaining force can load a relatively constant force, and the loading plate for load sharing transfers the force transferred by the worm screw jack step by step and finally evenly transfers the force to the boundary of the photoelastic model plate. The worm screw jack device is connected to the reaction frame to return the force to the pedestal, and the bottom support plate can realize the positioning of the photoelastic model plate and control its position.

2.3. Loading Plate Components for Load Sharing. The loading plate for load sharing is a part of the geo-stress loading device that is in direct contact with the photoelastic model 


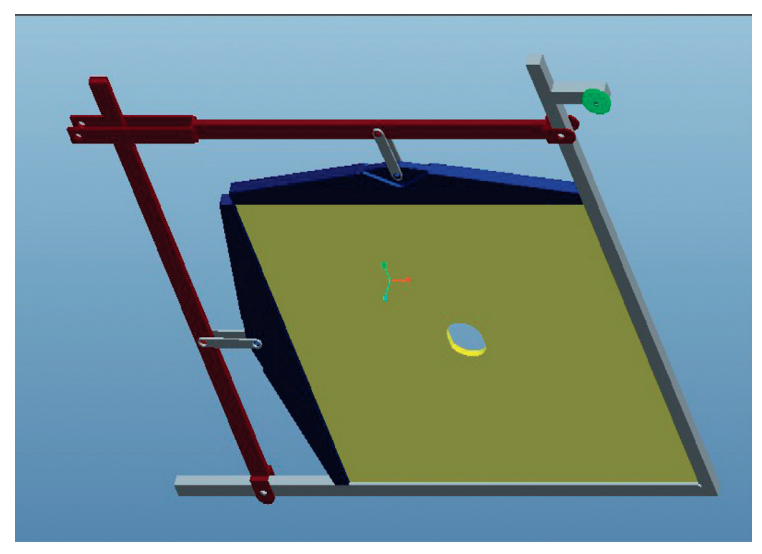

(a)

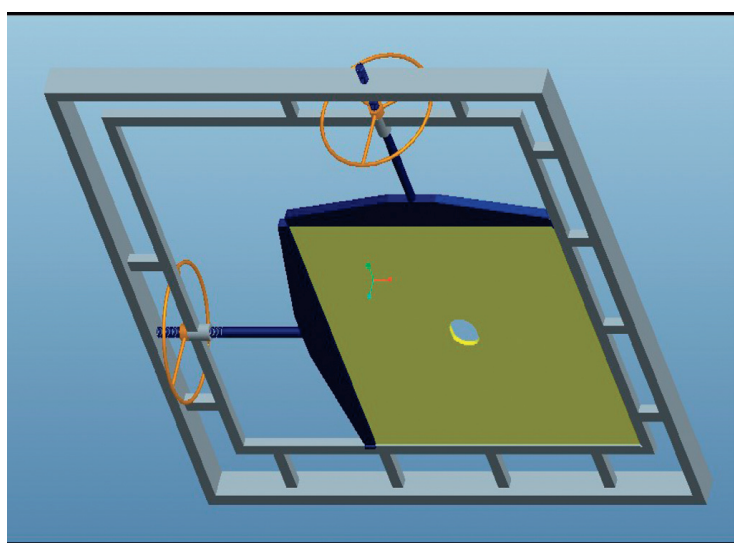

(b)

Figure 1: Preliminary schemes of the loading modes in the photoelastic test. (a) Lever loading. (b) Lead screw loading.

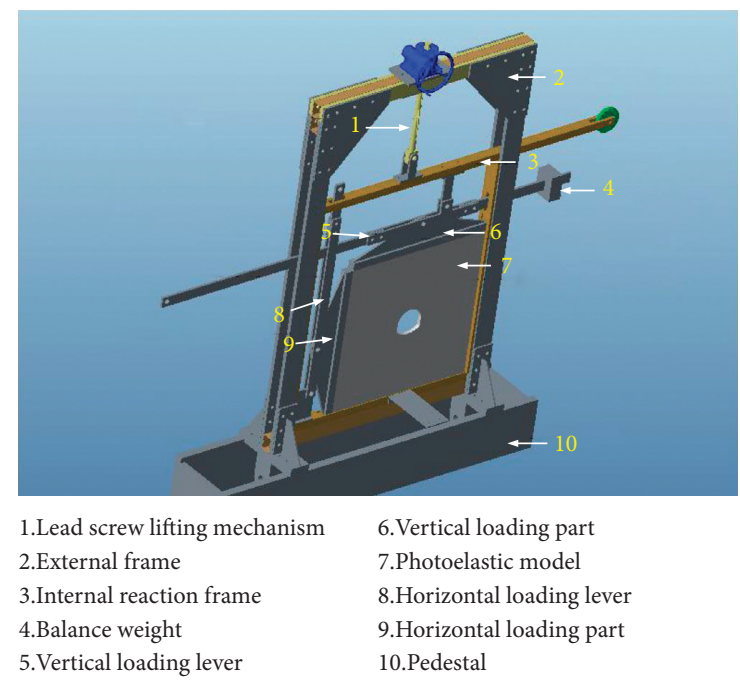

Figure 2: Model of the lever loading device.

plate, which is closely related to the stress distribution of the photoelastic model after loading. In the large-scale photoelastic model test, the photoelastic model size is much larger than that in the traditional photoelastic model test, which is expected to be $600 \mathrm{~mm}$ (height) $\times 600 \mathrm{~mm}$ (width) $\times 14 \mathrm{~mm}$ (thickness). The load transmitted by the worm screw jack should be evenly applied on the boundary of the large-scale model. Figure 4 presents the structural decomposition diagram of the loading plate for load sharing.

The concentrated load transmitted by the worm screw jack is directly transmitted to pressure beam 1 , and then the pressure beam uniformly transmits the load to the photoelastic model plate (with an area of $600 \mathrm{~mm} \times 14 \mathrm{~mm}$ ) through half load block 2, quarter load block 3, and oneeighth load block 4 in a step by step process. The pressure beam, half load block, and other load blocks are arranged in the form of a plane-to-edge contact from bottom to top, thereby forming the shape of a tower. The loading plate for load sharing incrementally divides the concentrated load equally and transfers it to the boundary of the photoelastic model to realize the application of a uniform load. To maintain the consistency of the load surface, long hole pins are set on both sides of the restraint plate to realize the positioning of each loading block.

\subsection{Loading Mechanism for the Universal Retaining Force.}

The geo-stress loading device uses a three-way screw loading scheme. If the screw-rod is rigidly connected to the loading part by threads, the following disadvantages will occur: due to the unavoidable influence of machining errors and installation errors, it is difficult to ensure good parallel contact between the loading surface of the photoelastic model and the loading surface of the loading parts for load sharing, and hence, the vertical load cannot be applied to the photoelastic model plate; when the unloading process occurs in the centre of the photoelastic model, the boundary of the photoelastic model will produce displacement, and the supporting force applied to the loading parts will decrease. This shows the preload decrease of the lead screw thread, and the preload of the thread will fluctuate greatly when the load changes, so it is difficult to guarantee a constant load on the photoelastic model. In view of the above two disadvantages, it is necessary to design a self-adjusting loading rod mechanism between the lead screw and the loading plate to ensure the stability of the load magnitude and direction.

\subsubsection{Universal Joint and Retaining Force of the Spring Guide} Rod. As shown in Figure 5, the surface of the photoelastic model plate has a certain inclination. When the loading plate is in parallel contact with the loading surface of the photoelastic model, the loading plate with the paper surface as the reference surface will rotate along the normal or horizontal axes, which requires the loading plate to set up the corresponding mechanism to reserve a certain degree of freedom for rotation in these two directions.

The rotational degree of freedom can be realized by a hinge connection. The rotational degree of freedom in two directions needs to be connected by pin shafts arranged in a cross to form a crosspin universal joint or directly connected by ball pins. To improve the convenience of manufacturing, the rotating part of the loading rod is realized by the crosspin 


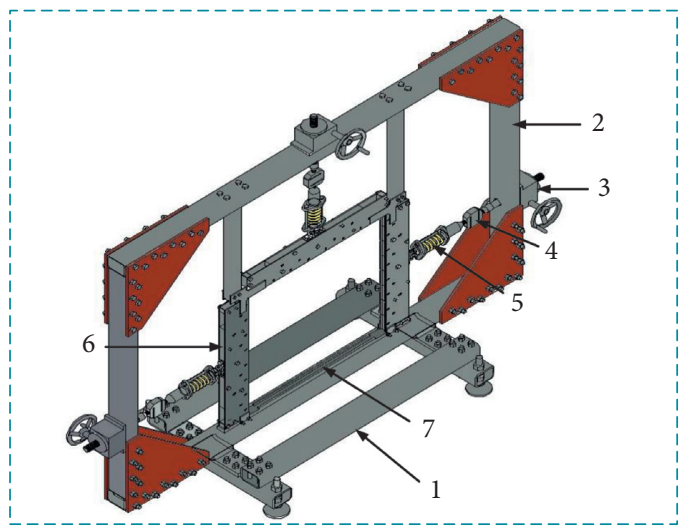
1. Pedestal
2. Reaction frame
3. Worm screw jack
4. Force sensor

\begin{abstract}
5. Loading mechanism for the universal retaining force

6. Loading plate for load sharing

7. Bottom support plate
\end{abstract}

(a)

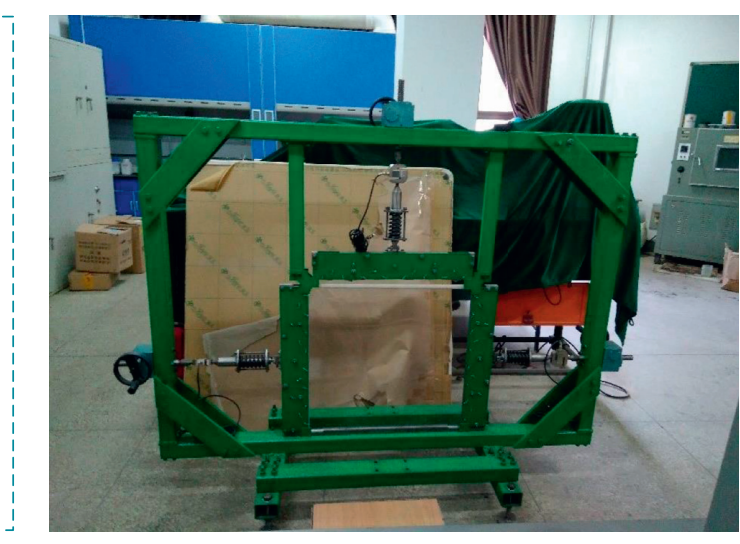

(b)

FIgURE 3: Three-directional uniform geo-stress loading device for the photoelastic test. (a) Schematic diagram of the geo-stress loading device component. (b) Actual object of the geo-stress loading device.
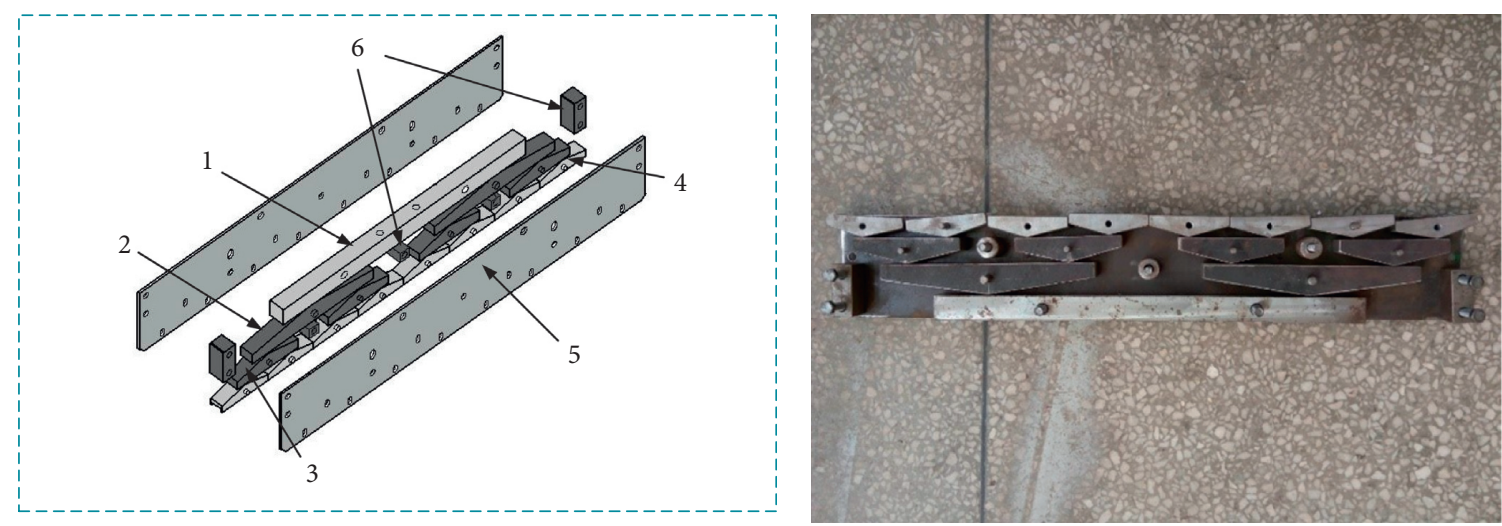
1. Pressure beam
2. Half load block
3. Quarter load block
4. One-eighth load block
5. Restraint plate
6. Block for maintaining a set distance

(a)

(b)

Figure 4: Structural decomposition diagram of the loading plate for load sharing. (a) Components of the loading plate for load sharing. (b) Actual object of the loading plate for load sharing.

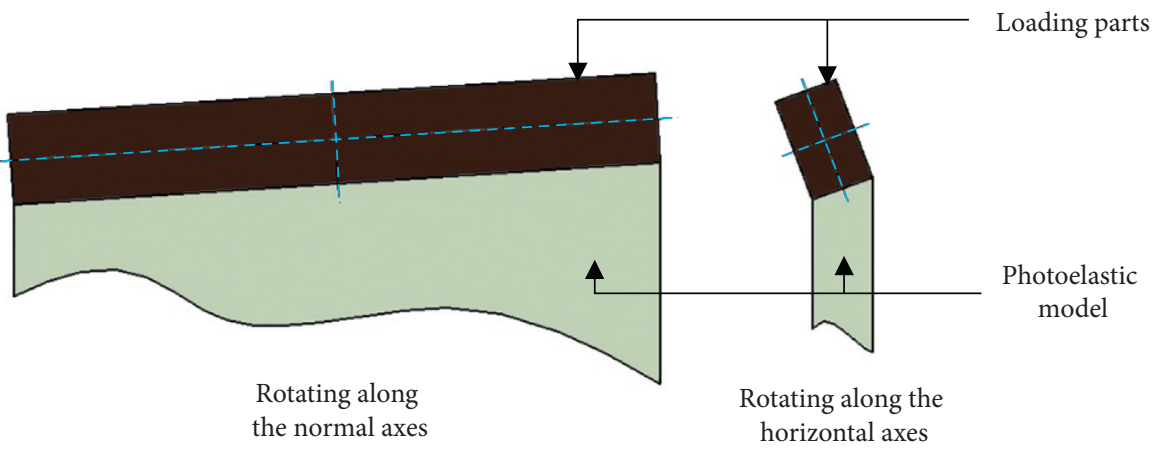

FIGURE 5: Rotation of the loading plate in contact with the inclined surface of the photoelastic model plate. 
universal joint; one end of the universal joint is connected to the pressure beam of the loading plate for load sharing to apply the load.

During the excavation unloading process inside the model tunnel in a photoelastic plate, to maintain a constant load, the retaining force of the spring and spring guide mechanisms are set on the upper part of the universal joint; when the boundary displacement of the photoelastic model occurs due to internal unloading, the spring can release its elastic potential energy to compensate for the load on the photoelastic model plate exerted by the loading parts. As the elastic deformation displacement of the photoelastic model is very small, the load can basically remain unchanged by using a spring with a larger stiffness. The loading mechanism for the universal retaining force designed according to the idea discussed above is shown in Figures 6 and 7.

\subsubsection{Strength Check for the Pin Shaft of the Universal Joint} and Calculation of the Retaining Force of the Spring. For the crosspin universal joint, the pin shaft is used for static loading. In the three-dimensional modelling design, the pin shaft with a nominal diameter of $d_{0}=8 \mathrm{~mm}$ is selected. The contact length between the lower connection of the universal joint and the pin shaft is $14 \mathrm{~mm}$, the contact length between the spring guide rod and the pin shaft is $12 \mathrm{~mm}$, and the contact length between the crosspin connecting block and the pin shaft is $16 \mathrm{~mm}$. The minimum contact length of $L_{\min }=12 \mathrm{~mm}$ is selected for calculation. The material of the pin shaft is $35 \#$ steel, its allowable shear stress is $[\tau]=$ $80 \mathrm{MPa}$, and its allowable extrusion stress under static load is $\left[\sigma_{p}\right]=120 \sim 150 \mathrm{MPa}$.

The concentrated load acting on the surface of the photoelastic model plate is $2872.8 \mathrm{~N}$ according to the similarity theory [28]. When the maximum load of the pin shaft is $F_{\max }=3000 \mathrm{~N}$, the extrusion stress and shear stress are as follows:

$$
\begin{gathered}
\sigma_{p}=\frac{F_{\max }}{d_{0} L_{\min }}=\frac{3000 \mathrm{~N}}{8 \mathrm{~mm} \times 12 \mathrm{~mm}}=31.25 \mathrm{MPa} \leq\left[\sigma_{p}\right], \\
\tau=\frac{F_{\max }}{(\pi / 4) d_{0}^{2}}=\frac{3000 \mathrm{~N}}{(3.14 / 4) \times(8 \mathrm{~mm})^{2}}=59.7 \mathrm{MPa} \leq[\tau] .
\end{gathered}
$$

Formulas (1) and (2) show that the pin with a nominal diameter of $8 \mathrm{~mm}$ meets the strength requirements.

According to the technical indexes of the worm screw jack that had been selected, the effective stroke of the screw is $80 \mathrm{~mm}$, of which $52 \mathrm{~mm}$ is served as the no-load movement stroke of the loading parts, the rest $30 \mathrm{~mm}$ is the loading compression stroke, that is, the maximum compression amount of the spring $\lambda_{\max }=30 \mathrm{~mm}$. Based on the installation space requirement of the spring, "design of cylindrical helical springs" (China National Standard GB/T 23935-2009) and "cylindrical helical spring seriate sizes" (China National Standard GB/T 1358-2009), the spring winding ratio is $C=5$, the effective turn of the spring is $N_{a}=6$, and the material of the spring is $65 \mathrm{Mn}$, shear modulus of which is $G=80 \mathrm{GPa}$.

The minimum stiffness of the spring is

$$
k_{\min }=\frac{F_{\max }}{\lambda_{\max }}=\frac{3000 \mathrm{~N}}{30 \mathrm{~mm}}=100 \mathrm{~N} / \mathrm{mm} .
$$

The minimum diameter of spring wire is

$$
d_{\min }=\frac{8 k_{\min } C^{3} N_{a}}{G}=\frac{8 \times 100 \mathrm{~N} / \mathrm{mm} \times 5^{3} \times 6}{8 \times 10^{4} \mathrm{MPa}}=7.5 \mathrm{~mm} \text {. }
$$

According to the size series table for ordinary cylindrical spiral springs, the recommended value of the spring wire diameter is taken as $d=8 \mathrm{~mm}$, and the spring parameters are as follows, where stiffness of the spring $k$ is

$$
k=\frac{G d}{8 C^{3} N_{a}}=\frac{8 \times 10^{4} \mathrm{MPa} \times 8 \mathrm{~mm}}{8 \times 5^{3} \times 6}=107 \mathrm{~N} / \mathrm{mm} .
$$

The mid-diameter $D$, inner diameter $D_{1}$, and major diameter $D_{2}$ of the spring are as follows:

$$
\left\{\begin{array}{l}
D=C d=40 \mathrm{~mm} \\
D_{1}=D-d=32 \mathrm{~mm} \\
D_{2}=D+d=48 \mathrm{~mm}
\end{array}\right.
$$

The spring pitch $p$ and helix angle $\alpha$ of the spring are as follows:

$$
\left\{\begin{array}{l}
p=(0.28 \sim 0.5) D \\
\alpha=\arctan \frac{p}{\pi d}
\end{array}\right.
$$

Taking $p=14 \mathrm{~mm}, \alpha=6.4^{\circ}$ can be calculated, which meets the requirements of distribution range $\left(\alpha=5^{\circ} \sim 9^{\circ}\right)$. The total length of spring $H_{0}$ is calculated by

$$
H_{0}=p N_{a}+1.5 d=96 \mathrm{~mm} \text {. }
$$

2.5. Worm Screw Jack. Because the uniform distribution load to simulate the geo-stress of the deep tunnel is applied on the plate for load sharing, a relatively large stroke is required for manual adjustment, the feed speed is slow, and the load is relatively stable. Through the research and comparative analysis of multiple schemes, the load application and stress adjustment are realized through the expansion and contraction of the worm screw. The accuracy of the load adjustment is substantially affected by the performance of the screw jack. The common lifting screw jack has the following limitations: short acting stroke, fast loading speed, difficult adjustment, and complicated installation; therefore, it is difficult to meet the needs of load application in the largescale photoelastic model test. After comparative analysis, the worm screw loading mechanism was adopted, as shown in Figure 8 .

The worm screw jack drives the worm gear mechanism by rotating the hand-wheel. The inner hole of the worm is a threaded hole, which is matched with the screw. The screw can be retracted and fed through the rotation of the worm gear. A sliding groove is arranged on the lead screw, which is 


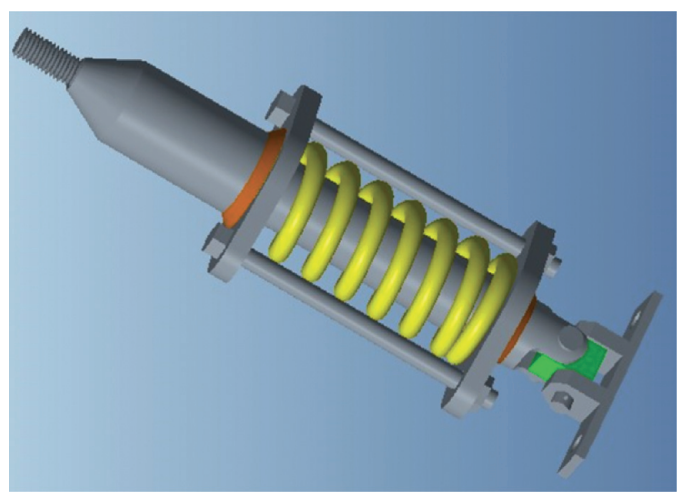

(a)

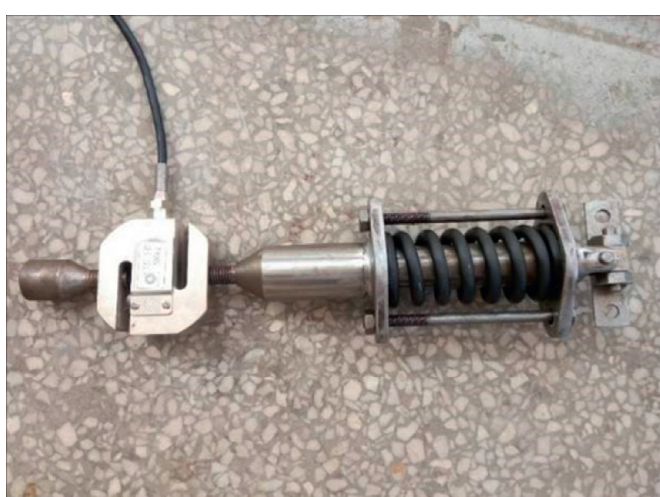

(b)

FIGURE 6: Loading rod mechanism for the universal retaining force. (a) 3D model of the loading rod mechanism. (b) Virtual object of the loading rod mechanism.

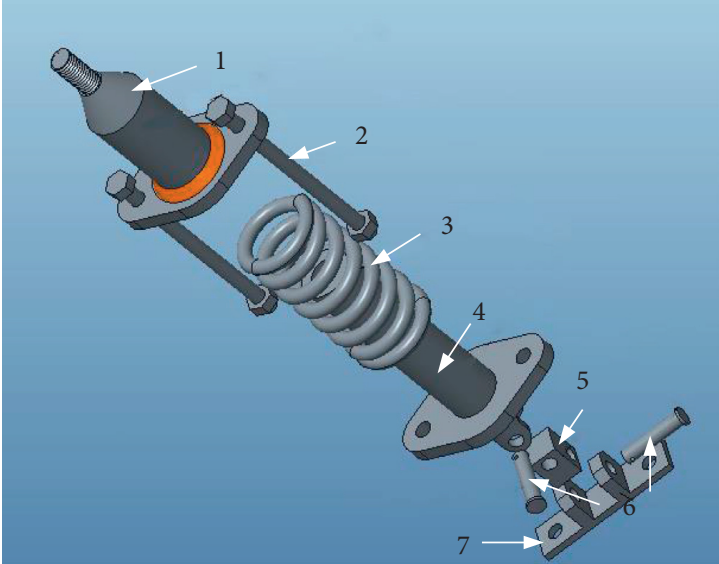

1. Spring guide rod sleeve

2. Connecting bolt

3. Retaining force spring

4. Spring guide rod
5. Cross pin connecting block 6. Pin shafts

7. Lower connection of the universal joint

Figure 7: Decomposition model of the loading rod mechanism for the universal retaining force.

matched with the sliding key in the jack shell, so that the lead screw can only move axially without rotation. The loading mode of the worm gear reducer allows the manual operation to reduce labour and exhibits higher adjustment accuracy. The main technical parameters of the worm screw jack selected by the geo-stress loading device are as follows: (1) load range: $0 \sim 10 \mathrm{kN}$; (2) effective stroke of the screw: $80 \mathrm{~mm}$; (3) loading torque of the hand-wheel: $0 \sim 2.6 \mathrm{~N} \cdot \mathrm{m}$; (4) loading rate: $0.12 \mathrm{~mm} /$ turn (hand-wheel); (5) box dimension: $136 \mathrm{~mm} \times 80 \mathrm{~mm} \times 82 \mathrm{~mm}$; and (6) connecting thread at the end of the screw: $\mathrm{M} 16 \times 1.5$.

\subsection{Reaction Frame and Base}

2.6.1. Reaction Frame. The photoelastic model plate is simultaneously loaded in three directions through the loading mechanism, and the reaction force generated by the loading mechanism returns to the base through the

reaction frame; therefore, the loading mechanism needs to be installed on the reaction frame, and the base is connected with the frame to maintain the stability of the geostress loading device. Finally, the frame is placed on the test bench and levelled. According to the light field range of the PA-420 photoelastometer, the size of the model plate, the layout requirements of the loading mechanism, the specification of the frame manufacturing materials, and comprehensive factors, such as the installation surface of the jack box located outside of the frame and the installation surface of the model support groove located inside of the frame, the size of the reaction frame is determined to be $1700 \mathrm{~mm} \times 1180 \mathrm{~mm}$.

The frame is usually made of section steel, which is commonly used in metal engineering. Combined with the frame stress conditions, stiffness requirements, difficulty associated with the installation of the loading mechanism on the frame, convenience of manufacturing, and other factors, an $80 \mathrm{~mm} \times 60 \mathrm{~mm} \times 5 \mathrm{~mm}$ cold-formed hollow rectangular steel tube is selected as the frame material. The frame is rectangular in shape and is formed by four connected rectangular tubes. The connection mode can be a bolt connection or weld. Welded frames have the advantages of convenient manufacturing and low cost, but they have the following disadvantages: large deformation, difficulty repairing the installation holes on the frame after welding, and inconvenient transport of the whole frame in the laboratory. Therefore, the reaction frame finally adopts the bolt connection. In the middle of the reaction frame, two positioning frames connecting the loading parts are installed to position the loading mechanism, and the reaction frame structure is shown in Figure 9.

2.6.2. Base. The base of the device shall meet the following requirements: (1) guarantee the whole device stable and safe enough to avoid accidents caused by toppling during testing operation, (2) the connection between the base and the frame shall be firm and reliable to facilitate installation and adjustment, (3) the excavation unloading device developed in this paper shall be conveniently installed on the base, (4) the base 


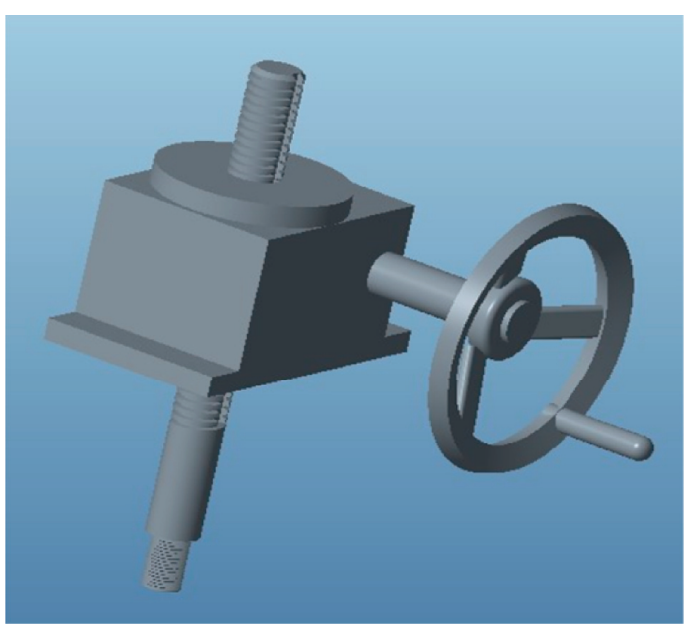

(a)

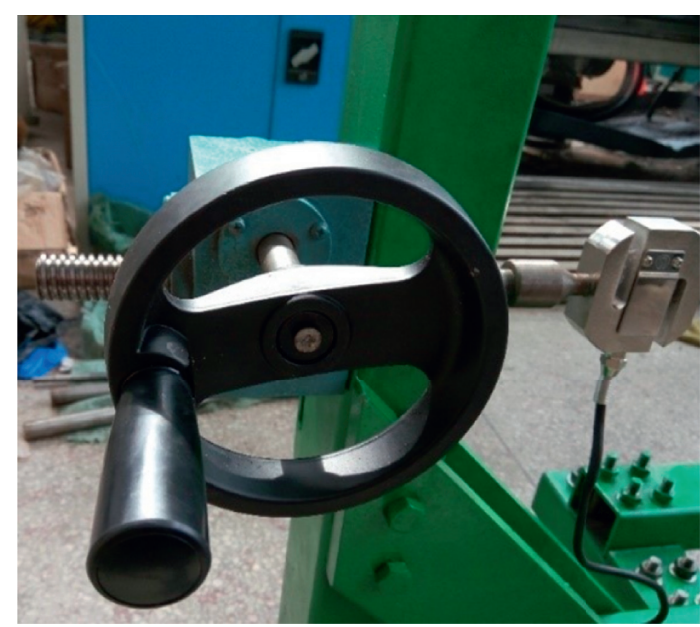

(b)

FIGURE 8: Worm screw jack. (a) 3D model of the worm screw jack. (b) Virtual object of the worm screw jack.

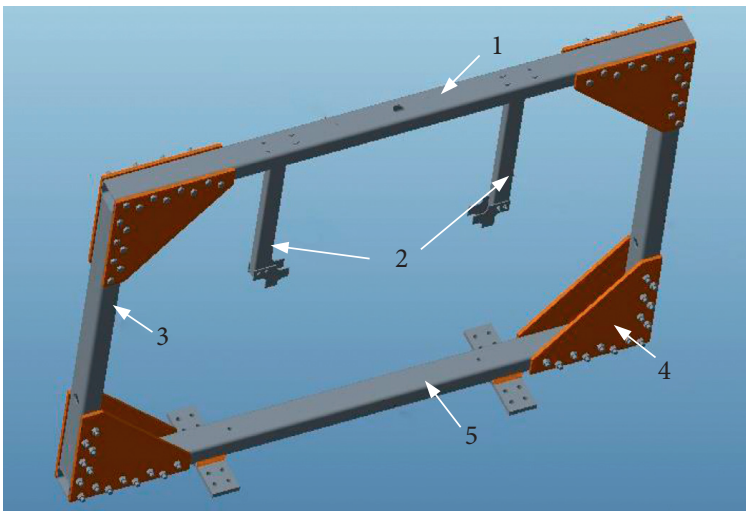

1. Frame upper beam 2. Positioning frames 3. Frame column

4. Frame connection plate

5. Frame lower beam

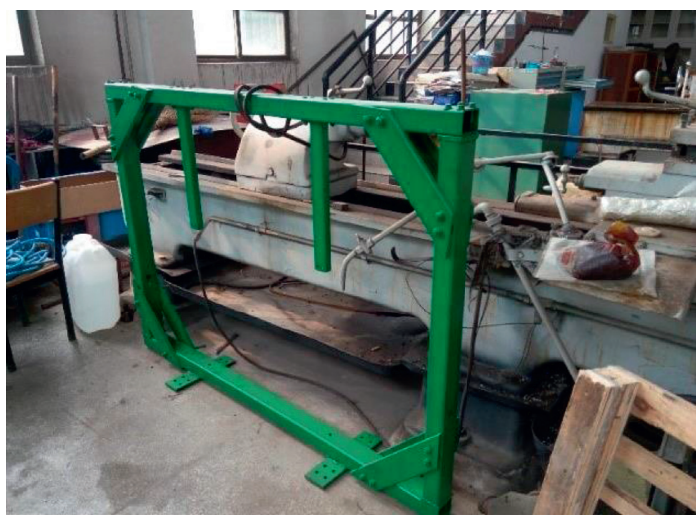

(a)

(b)

FIGURE 9: 3D model and structure of the reaction frame. (a) 3D model of the frame. (b) Virtual object of the frame.

shall level the geo-stress loading device to allow the photoelastic model to be in the correct test position, (5) the base should be able to be placed between the two polarizers of the photoelastic instrument, and the height should be such that the model is in the centre of the polarized light field, and (6) the design of the base needs to control the overall dimension.

The base is made up of a rectangular steel tube with the same specification as that of the reaction frame. The lower beam of the frame is welded with a connecting plate, which is connected to the base by bolts. The base is supported by an adjustable foundation, which can adjust the height and keep the geo-stress loading device stable. The two supporting beams of the base are connected to the two beams by bolts so that the integrity of the base is maintained. At the same time, the excavation unloading device to simulate the deformation response for the model tunnel excavation can be installed on the beam. The three-dimensional model and the virtual object of the base are shown in Figure 10.

\subsubsection{Deformation Analysis of the Reaction Frame.} During the loading process, the inside of the reaction frame is subjected to the force of the loading mechanism, and the four sides of the frame produce certain deformation. The frame needs to have sufficient stiffness to ensure the stability and accuracy of the exerted load. The 3D model of the reaction frame built by using Creo software is imported into the ANSYS model to build the modules, and the model tools in ANSYS are used to set the surface mark as the local stress or constraint area at the actual stress position of the upper beam, the lower beam, and the column, and the connection position of the lower beam. The mesh tool is used for mesh generation. Method is added to the mesh and set to automatic mode. Two-directional deformation solving projects are added in solution, the directions are set to $Y$ and $Z$, and then a total deformation project is added. The whole frame is selected as the object, and the deformation response of each part of the reaction frame is obtained under the maximum 


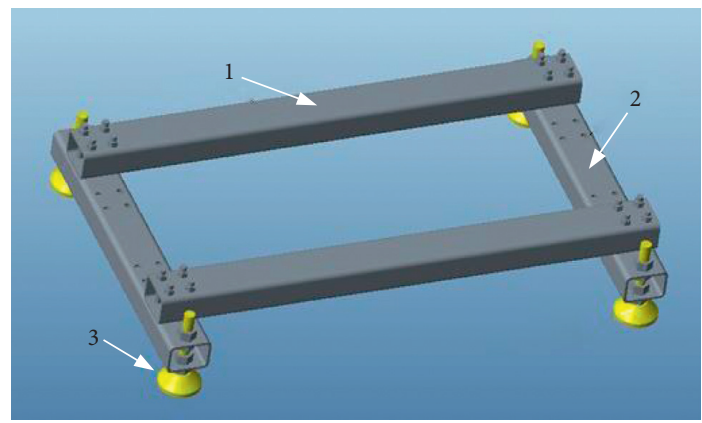

1. Beam

2. Supporting beam

3. Adjustable foundation

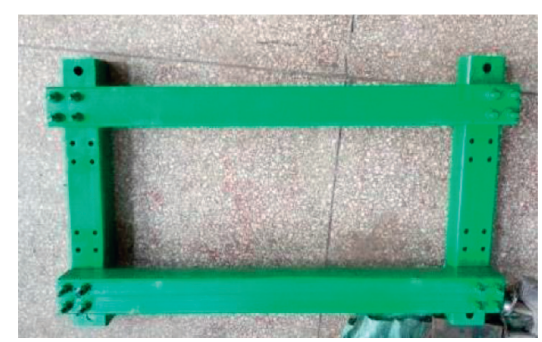

(b)

Figure 10: 3D model and virtual object of the base assembly. (a) 3D model of the base. (b) Virtual object of the base.

load; the calculation results for the reaction frame displacement are shown in Figure 11. According to the numerical calculation results, the maximum deformation position is in the middle of the upper beam of the reaction frame, and the value is $0.475 \mathrm{~mm}$. The deformation of the frame can meet the test requirements, and the design scheme is feasible.

\section{Excavation Unloading Devices for Large-Scale Photoelastic Tests}

The excavation unloading device is a mechanical mechanism designed to simulate the surrounding displacement response caused by the model tunnel excavation effect in photoelastic model tests. Through the gradual contraction of the excavation unloading device, the whole process of tunnel deformation caused by excavation from the sudden unloading of stress to the redistribution balance, is simulated. Thus, the stress variation law of each support unit and surrounding rock mass is obtained, and then the stress characteristics of each support unit in the surrounding rock mass and composite support structure system and its sharing role in the adjustment process are analysed.

\subsection{Excavation Unloading Device}

3.1.1. Support Block. The excavation unloading device should be placed in the model tunnel to support the boundary of the tunnel profile cut by an engraving machine in the photoelastic model plate, and the support block should be closely fitted with the tunnel profile. Therefore, the support block should be designed according to the size of the complete model tunnel and then cut into several parts after processing. The material between the cutting seams needs to be removed so that the support block can contract inward without mutual interference. The forming process of the support block is shown in Figure 12.

Theoretically, each point on the contour of the model tunnel moves along its normal line in ideal contraction motion. However, it is impossible to cut the support blocks into infinite numbers in the actual design. After analysis, the invert and arch of the model tunnel are divided into two parts, with two parts for the side wall, and there are six parts in total. The hinge points are distributed according to the regular hexagon at the end face of the support block. Such segmentation and articulation methods are close to the ideal form of the contraction motion in the case of displacement of a short distance.

\subsubsection{Umbrella-Shaped Expansion and Contraction} Mechanism. The two ends of the support block are hinged with umbrella-shaped expansion and contraction mechanisms on the lead screw, as shown in Figure 13.

The umbrella-shaped expansion and contraction mechanism is composed of left and right screw rods, left and right hinged disc nuts, and 12 connecting rods. The umbrella-shaped expansion and contraction mechanism can convert the rotation of the lead screw into the reverse constant velocity movement of the nuts of the two hinged plates along the axial direction of the lead screw, and the axial movement of the nut parts is converted into the radial displacement of the support block through the connecting rod mechanism. M16 $\times 1.5$ common thread is used for the left and right screw threads. The shape of the hinge plate nut and connecting rod is complex, resulting in manufacturing difficulties. The design can be simplified during processing and manufacturing.

3.1.3. Support and Guide Rod. The structural model of the support and guide rod is shown in Figure 14. The support is composed of a base and a support rod. The base is connected and fixed with the base of the geo-stress loading device. A shaft sleeve is designed on the support rod to rotate with the polished part of the rod of the lead screw. The axial direction of the lead screw is positioned by the four circlips installed on the slotted polished rod of the lead screw and the end face of the shaft sleeve. The height of the support can be adjusted so that the excavation unloading device is at the same height as that of the model tunnel. In the view of the torque problem for the balance screw, a guide rod mechanism is designed on the support rod; one end of the guide rod is 

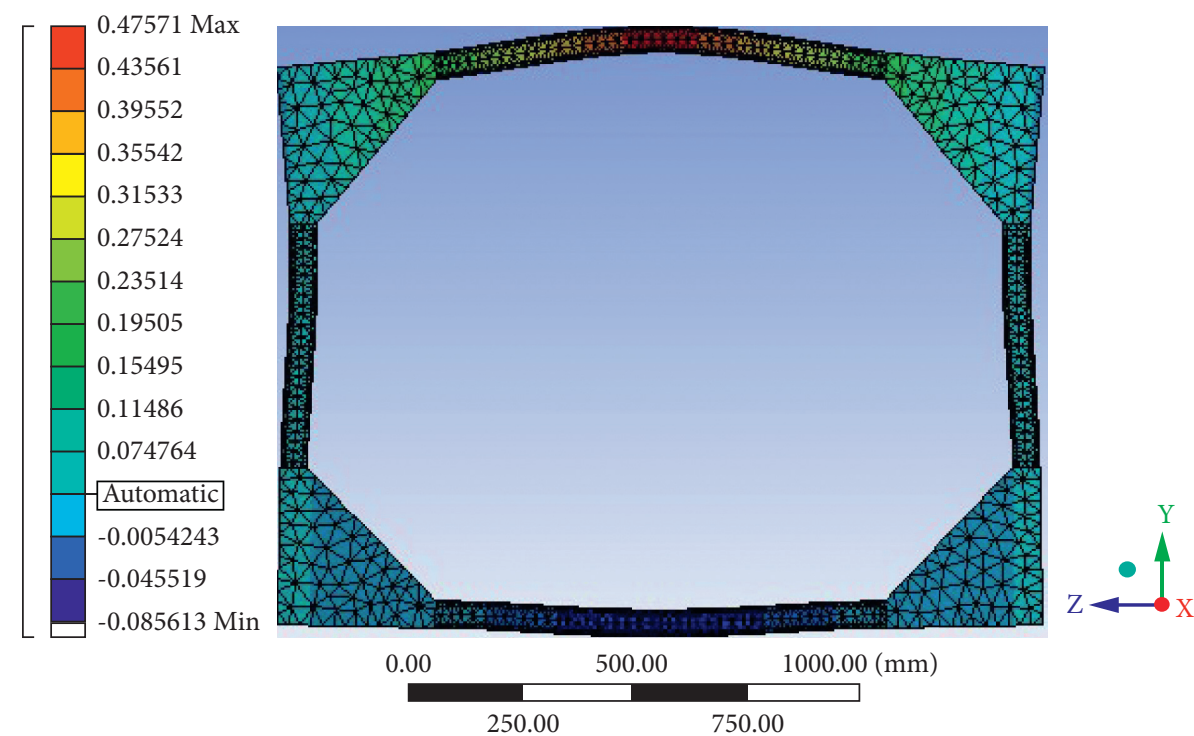

(a)
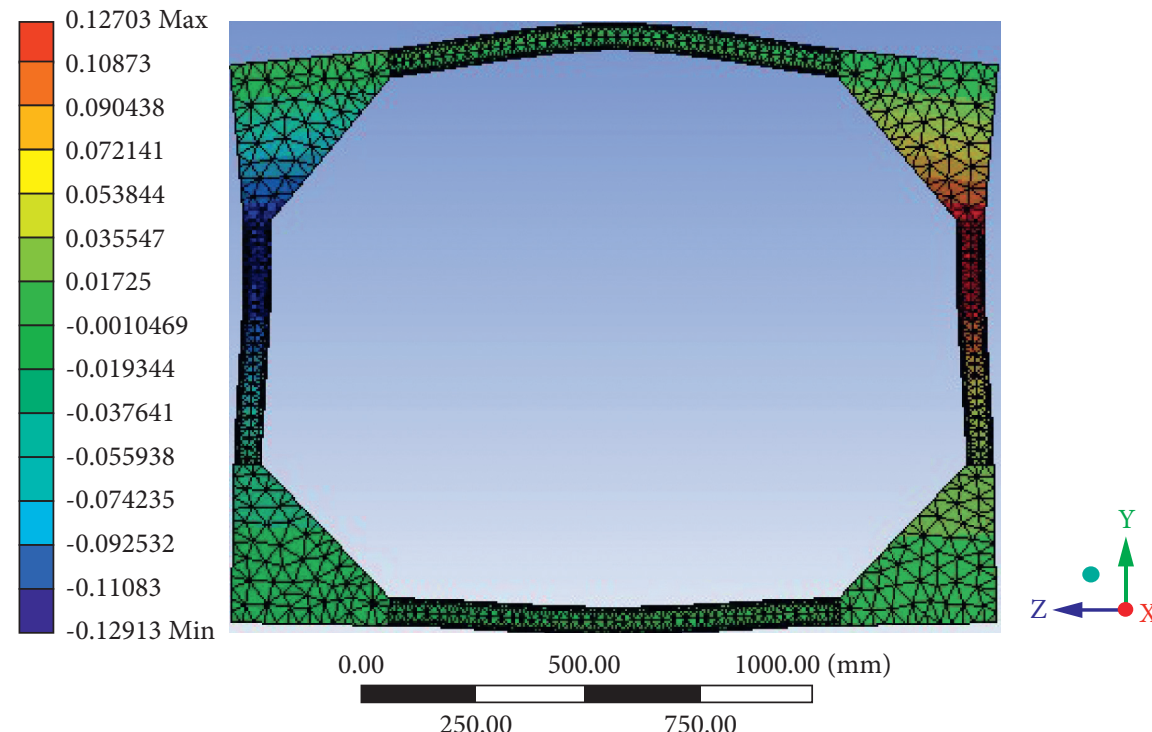

(b)

Figure 11: Continued. 


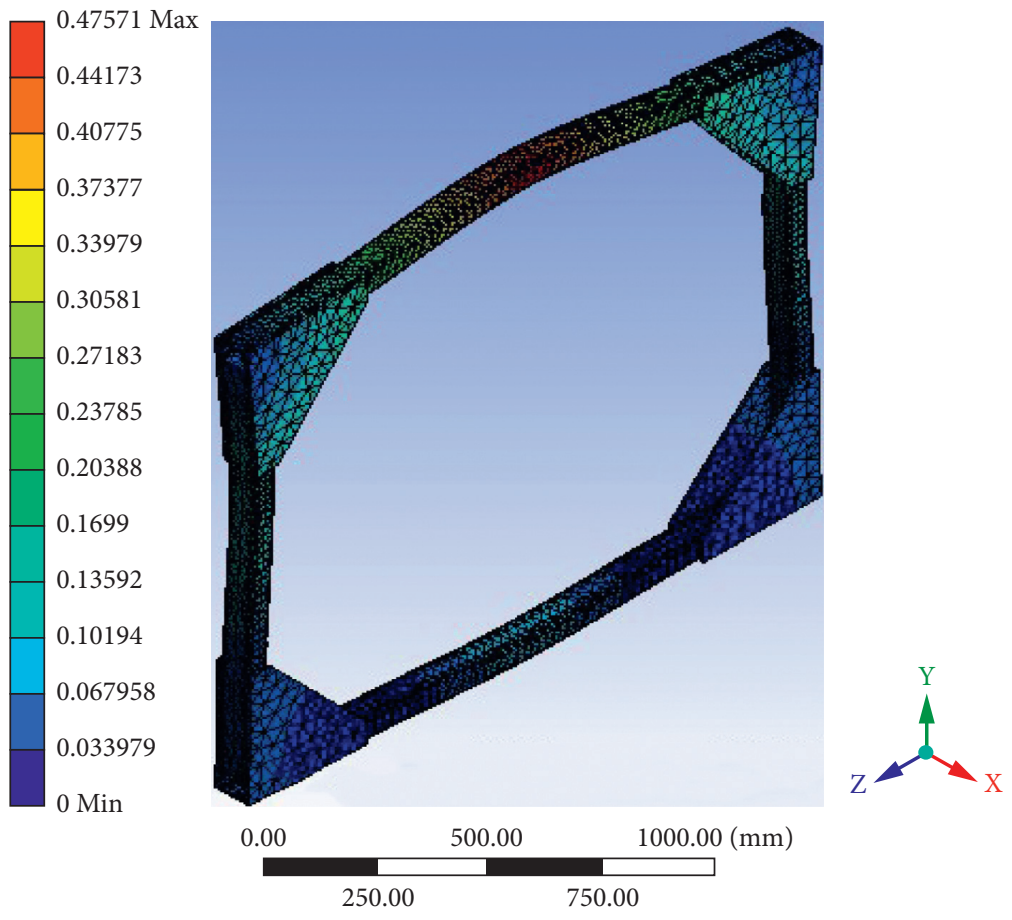

(c)

FIGURE 11: Numerical calculation results for the deformation of the reaction frame. (a) Displacement contour value of the frame in the $Y$ direction. (b) Displacement contour of the frame in the $Z$ direction. (c) Total displacement contour of each part of the frame.

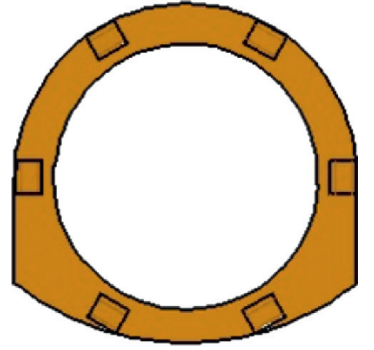

(a)

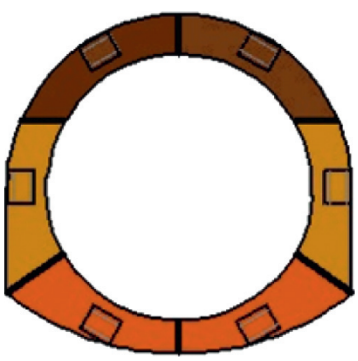

(b)

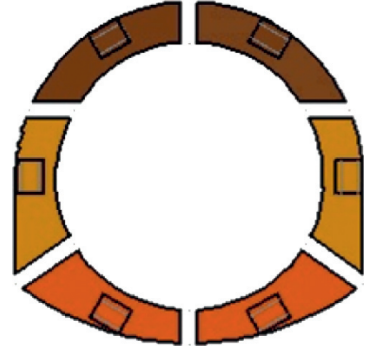

(c)

Figure 12: Schematic diagram of the forming process of the support block. (a) Complete outline. (b) Cutting the seams. (c) Removal of the seam material.

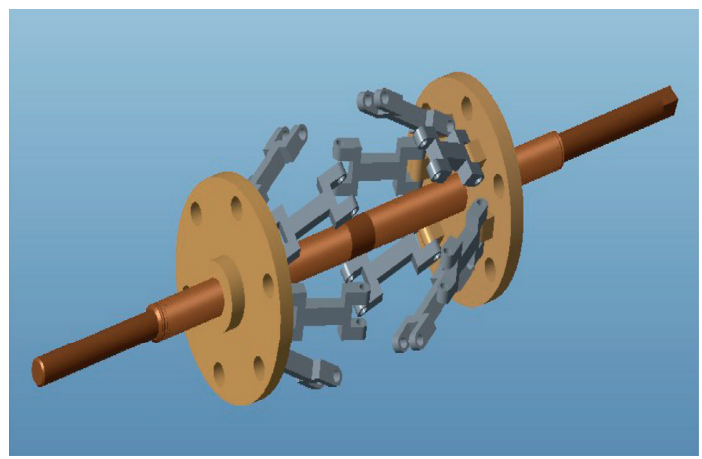

Figure 13: The umbrella-shaped expansion and contraction mechanism. 


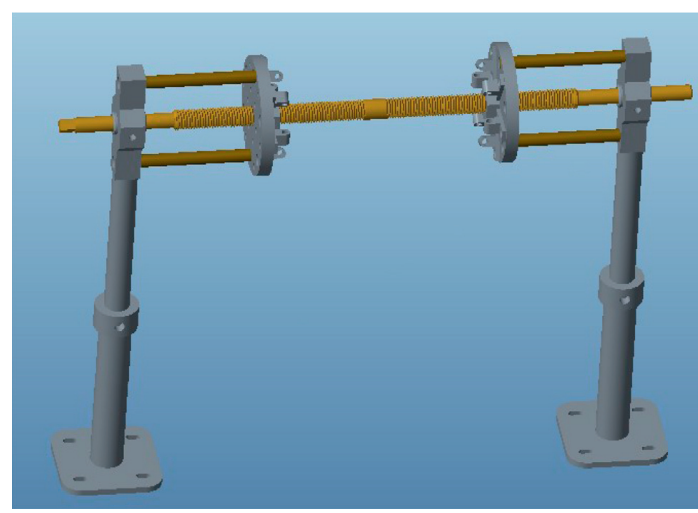

FIGURE 14: Support and guide rod model.

connected with the hinge plate nut, and the other end of the smooth rod and the support rod form a sliding pair, which does not affect the axial movement of the hinge plate nut but can also offset the torque transmitted by the screw, effectively reducing the impact of the external force on the test.

3.1.4. Model Assembly and Manufacturing of the Excavation Unloading Device. The three-dimensional model and virtual object of the excavation unloading device are shown in Figure 15. The assembly process is as follows: (1) the support model is imported in the Creo section and defined as the default mode; (2) the guide rod is installed on the umbrellashaped expansion and contraction mechanism assembly and defined as a rigid connection; (3) the components in Step 2 and the support are assembled, and the screw and shaft sleeve of the support rod are connected with the pin; (4) each support block is installed and connected with the bar on both sides by pin; and (5) finally, the connections between the hand-wheel and screw are defined as rigid connections.

\subsection{Support Block Slot and Displacement Error Analysis}

3.2.1. Calculation of the Support Block Slot. After the support block is processed and manufactured according to the complete outline, it is divided into 6 blocks according to the design requirements. To make the support block contract inward after assembly, it is necessary to mill a certain thickness of material on the cutting surface. If the machining amount is too large, the contact area between the support block and the model tunnel will be reduced, and the test effect will be affected; if the machining amount is too small, it cannot meet the full-displacement release requirements of the model tunnel, which shows that the contraction displacement is not sufficient, and the support block cannot be completely separated from the model tunnel profile. Therefore, it is necessary to calculate the machining quantity of the cutting surface of each support block so that the best test effect can be achieved.

The maximum displacement of the tunnel profile in the photoelastic model needs to be calculated to confirm the relationship between the machining amount and the maximum displacement of the model tunnel. The geometric similarity ratio between the model tunnel and the prototype tunnel is $1: 50$. The deformation is calculated according to the prototype tunnel and then converted into the displacement of the model tunnel based on the geometric ratio. To simplify the calculation, the cross-section of the tunnel is simplified as a circle, as shown in Figure 16, where $p$ is the vertical geo-stress and $\lambda$ is the lateral pressure coefficient. To ensure the maximum displacement value, the calculation is carried out according to the related parameters of Grade $\mathrm{V}$ surrounding rock mass [29], where gravity is $\gamma=20 \mathrm{kN} / \mathrm{m}^{3}$, the elastic modulus is $E=1 \mathrm{GPa}$, and Poisson's ratio is $\mu=0.35$.

The vertical geo-stress is calculated under the condition that the depth of the tunnel is $1200 \mathrm{~m}$,

$$
p=\gamma H_{\max }=20 \frac{\mathrm{kN}}{\mathrm{m}^{3}} \times 1200 \mathrm{~m}=2.4 \times 10^{7} \mathrm{~Pa},
$$

and the displacement is determined according to the following formulas:

$$
\left\{\begin{array}{l}
u=\frac{p r_{0}^{2}}{4 G r}\left\{(1+\lambda)+(1-\lambda)\left[4(1-\mu)-\frac{r_{0}^{2}}{r^{2}}\right]\right\} \cos 2 \theta, \\
v=-\frac{p r_{0}^{2}}{4 G r}(1-\lambda)\left[2(1-2 \mu)+\frac{r_{0}^{2}}{r^{2}}\right] \sin 2 \theta,
\end{array}\right.
$$

where $G$ is the shear modulus $(G=E /(1+2 \mu)), \lambda$ is the lateral pressure coefficient $(\lambda=0), r$ is the radius, and $\theta$ is the coordinate angle.

According to the above calculation formulas for surrounding rock mass displacement of the circular tunnel without support, the following displacement along the tunnel profile can be obtained at $r=r_{0}=2.6 \mathrm{~m}$ :

$$
\left\{\begin{array}{l}
u=0.143 \cos 2 \theta \\
v=-0.164 \sin 2 \theta .
\end{array}\right.
$$

That is, the maximum displacement of the prototype tunnel is $0.164 \mathrm{~m}$. According to the geometric similarity ratio, the maximum displacement of the model tunnel is $3.28 \mathrm{~mm}$, which is regarded as the basis when calculating the machining amount of the support block. The support blocks are symmetrically arranged on both sides, and hence, the milling amount of the three support blocks on one side only needs to be calculated. Figure 17 shows the position of each support block before and after displacement, and the black deepened part in the figure is the part that is milled. According to the displacement requirements and the geometric relationship before and after displacement, the machining amount of each support block is calculated as follows: the upper end and the lower end of the upper support block are $1.7 \mathrm{~mm}$ and $2.9 \mathrm{~mm}$, respectively; the lower end of the side support block is $1.9 \mathrm{~mm}$; and the upper end and the lower end of the lower support block are $1.5 \mathrm{~mm}$ and $1.7 \mathrm{~mm}$, respectively.

3.2.2. Error Analysis of the Contour Displacement. The support block is designed to divide six parts and contract inward to release the displacement. During contraction, 


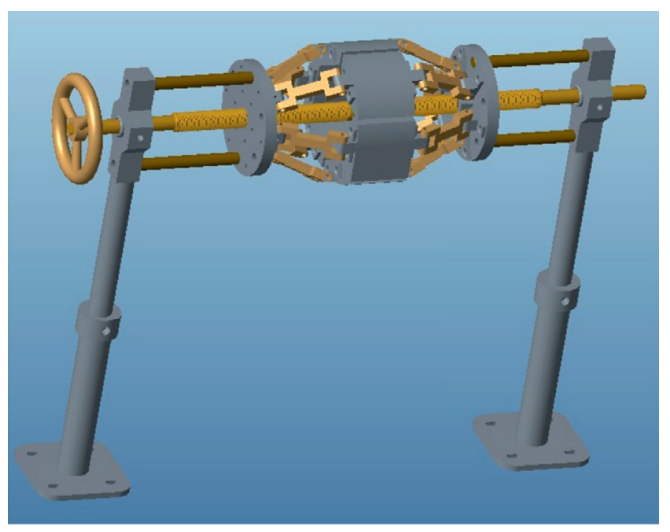

(a)

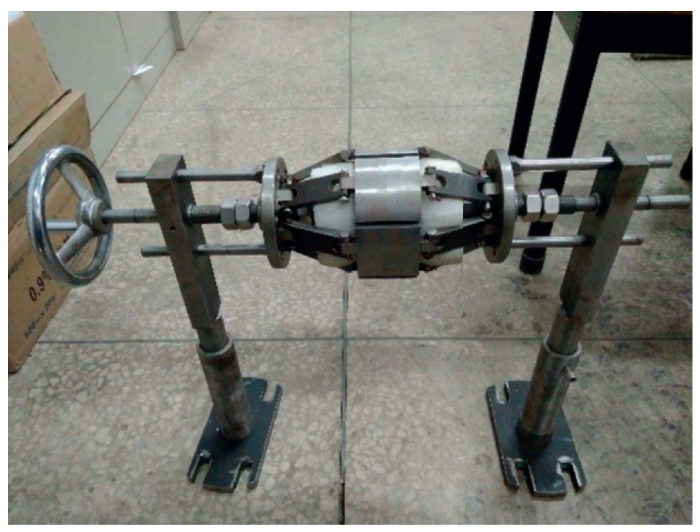

(b)

Figure 15: Excavation unloading device. (a) 3D model of the excavation unloading device. (b) Virtual object of the excavation unloading device.

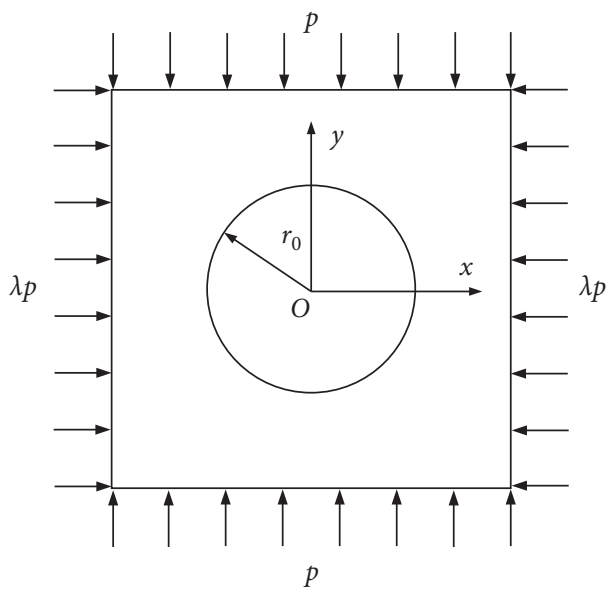

Figure 16: Simplified mechanical model of the photoelastic test.

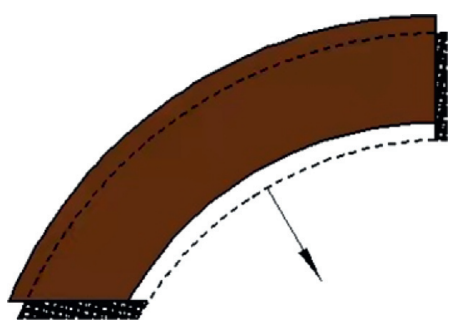

(a)

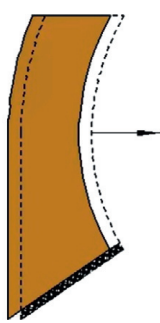

(b)

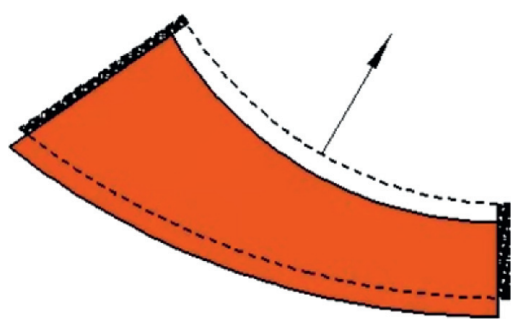

(c)

FIGURE 17: Schematic diagram of cutting the support block. (a) Upper support block. (b) Side support block. (c) Lower support block.

the contour line of the support block does not strictly contract according to the similar shape of the model tunnel; therefore, it is necessary to analyse the displacement of the contour line of the support block. The displacement error is obtained by comparing the actual contraction displacement with the ideal displacement. Figure 18 presents the error analysis for the contour displacement, where $O$ is the centre of the ideal contour and $O_{1}$ is the centre of the actual contour. According to the geometric relationship in the figure, the displacement error can be obtained as follows:

$$
\Delta x=\left|R\left(\frac{\sin \theta_{2}}{\sin \left(\pi-\theta_{1}\right)}-1\right)+x\right| .
$$

Formula (12) can be used as a reference for controlling the contour displacement during the test. The farthest edge point of the upper support block is taken as an example, 


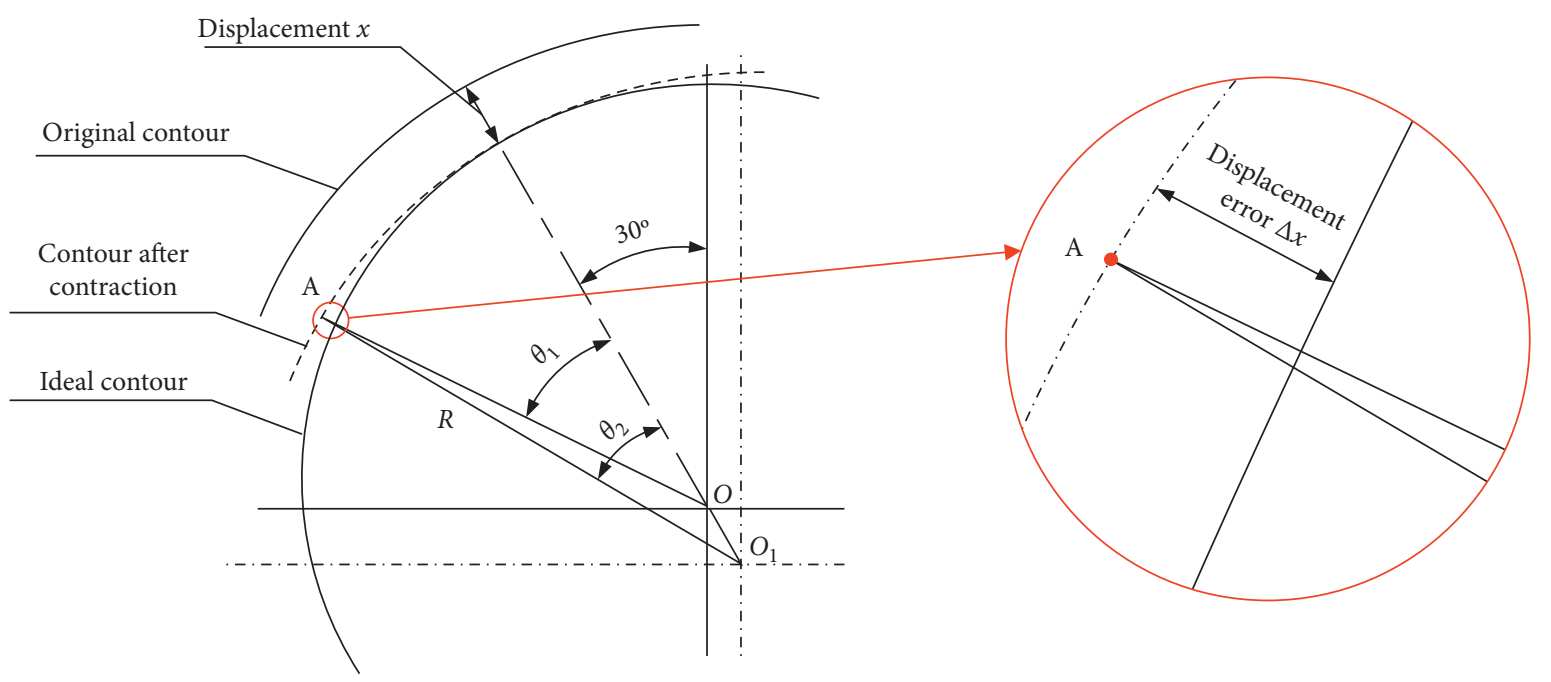

FIGURE 18: Sketch map of the displacement error.

where $\theta_{1}=40.52^{\circ}, \theta_{2}=37.38^{\circ}, x=3.28 \mathrm{~mm}$, and $R=52 \mathrm{~mm}$. The maximum displacement error of the upper support block for $\Delta x=0.13 \mathrm{~mm}$ can be obtained. According to the test requirements, the displacement plus the error value is taken as the actual operation displacement.

\section{Verification Tests for the Effect of Geo-Stress Loading and Excavation Unloading Devices}

To verify the performance of the geo-stress loading and excavation unloading devices of the large-scale photoelastic model test for deep tunnels, some tests for verifying the effect of geo-stress loading and excavation unloading devices were performed. The testing process is as follows. (1) Construction of the test model: by using the single edge milling cutter of the programming control engraving machine, as shown in Figure 19(a), a horseshoe-shaped tunnel section was cut and processed on a PMMA (polymethyl methacrylate) plate and epoxy resin photoelastic plate with a size of $600 \mathrm{~mm} \times 600 \mathrm{~mm} \times 14 \mathrm{~mm}$ (length $\times$ width $\times$ thickness). Furthermore, the epoxy resin photoelastic model shown in Figure 19(b) was prepared by drilling the bolt (cable) holes, stress relieving and setting the composite support system (bolts, cables, and spray layer). (2) Loading simulation: after cutting the model tunnel, the PMMA plate was installed on the geo-stress loading device and connected to the loading sensor, dynamometer, and computer, and the control software was debugged to make the display channel consistent with the sensor input channel. Before the loading parts were in contact with the loading surface, the sensor was set to zero using the control software. All three directions were loaded to the maximum value of the designed load by turning the screw jack hand-wheel, and the load stability, adjustment accuracy, stability time, and the state of the device during loading were observed, as shown in Figure 19(c). (3) Excavation unloading simulation: the anchored model tunnel was installed on the self-developed geo-stress loading device, and the excavation unloading device was installed on the pneumatic automatic balance bed so that the support block passed through the model tunnel, and the middle position of the support block was facing the profile surface. The hand-wheel was rotated to make the support block come in contact with the profile surface of the model tunnel, as shown in Figure 19(d). The vertical and horizontal loads were applied to the predetermined values by the geo-stress loading device, and then the excavation unloading device was used for unloading step by step to simulate the tunnel excavation effect. The PA-420 photoelastometer was used to produce the bright-field isochromatic fringes, and the bright-field isochromatic fringes under different excavation unloading conditions were recorded by using the automatic image acquisition system.

4.1. Performance of the Geo-Stress Loading Device. The loading condition in the verification test for geo-stress loading device (see Figure 20) showed that the three directions were loaded to more than $3000 \mathrm{~N}$, and the current loads in the upper, left, and right directions were $3089.0 \mathrm{~N}$, 3097.7 N, and $3110.8 \mathrm{~N}$, respectively, which could reach the maximum designed load. The red line displayed on the interface represented the force-time relationship, which indicated that the load maintained a constant level after applying the predetermined testing load by the use of the geo-stress loading device. In the verification tests, two loading modes were tested, namely, first vertical loading and then horizontal loading and first horizontal loading and then vertical loading. The results showed that the load can be stable after 5 8 minutes, the load adjustment accuracy was less than $5 \mathrm{~N}$, and the stability time was almost independent of the load magnitude and loading sequence.

4.2. Performance of the Excavation Unloading Device. During the test, the upper, lower, and side support blocks of the excavation unloading device can be in close contact with the profile surface of the model tunnel; the support of the 


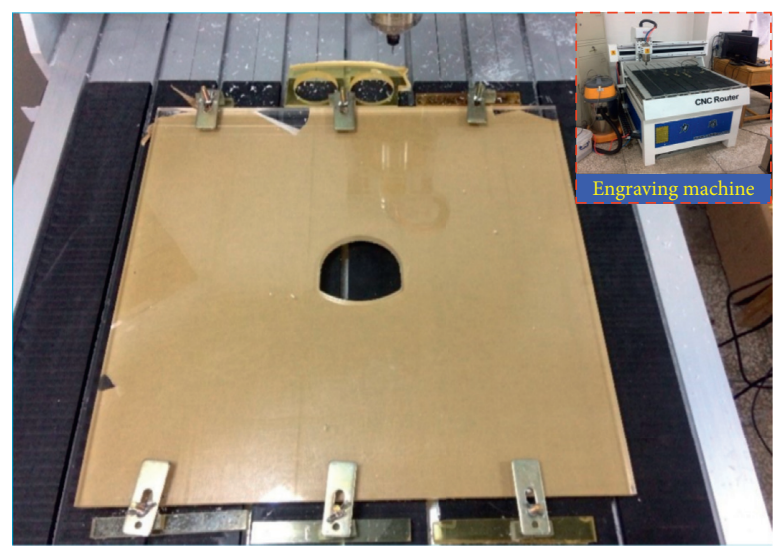

(a)

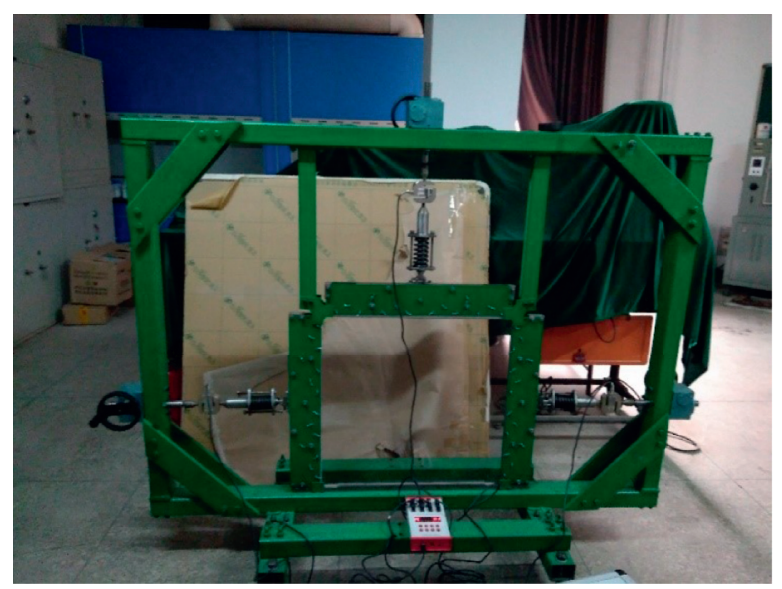

(c)

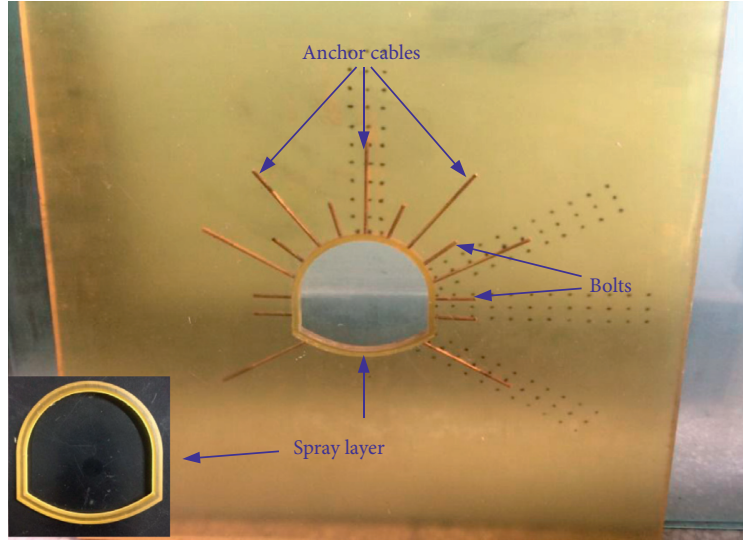

(b)

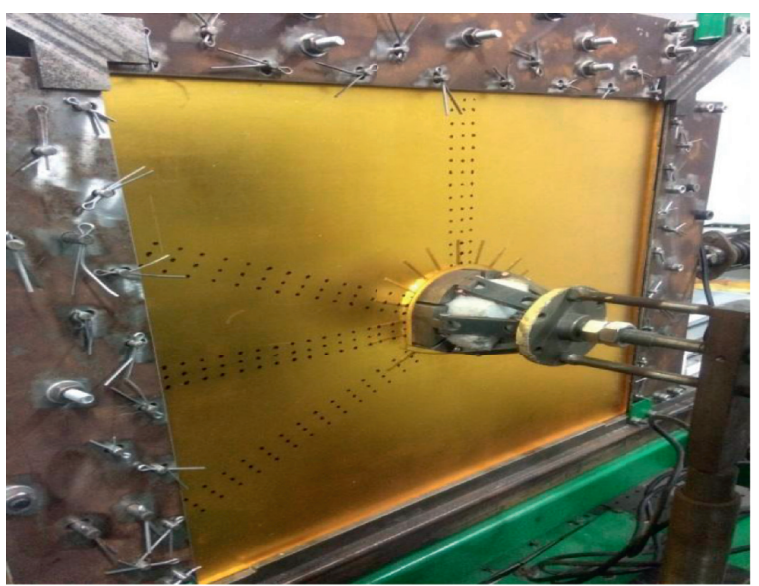

(d)

Figure 19: Verification tests for the effect of geo-stress loading and excavation unloading devices. (a) Model tunnel cutting. (b) Anchored photoelastic model. (c) Loading test. (d) Excavation unloading test.
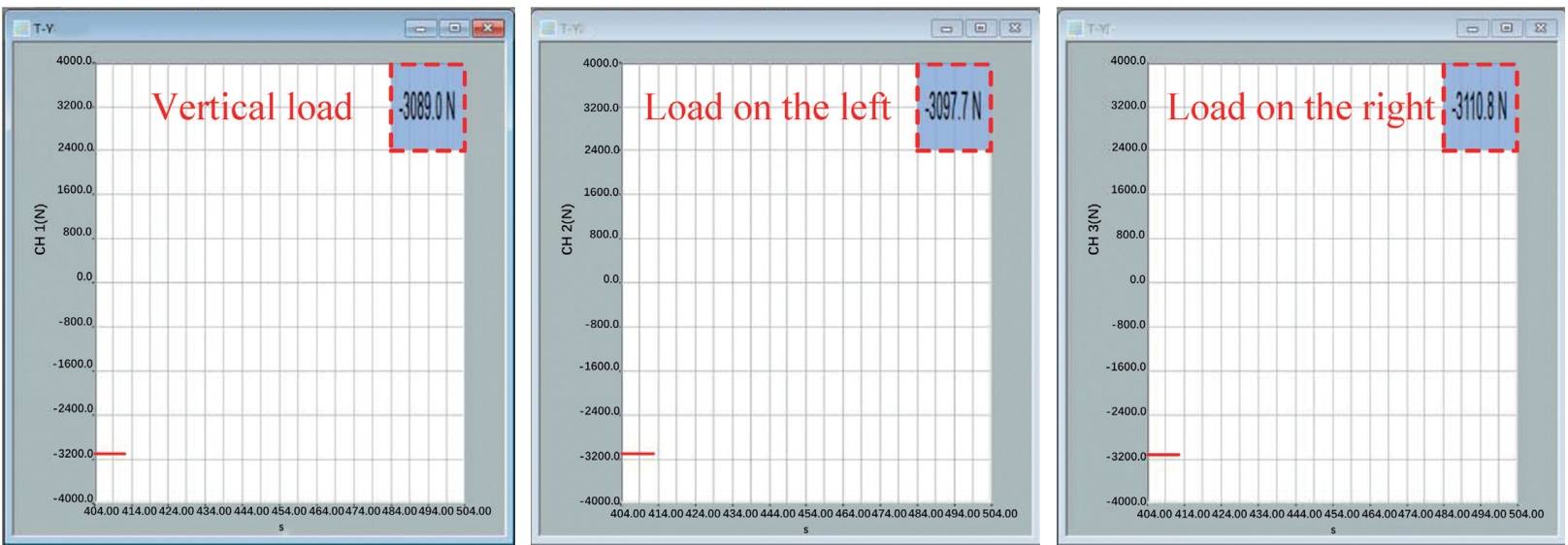

FIGURE 20: Loading conditions in the verification test for geo-stress loading device.

rotating hand-wheel is stable and firm, the contraction action of the excavation unloading device is flexible, and the operation control is simple.

In the verification tests for the excavation unloading device used in the anchored photoelastic model, with the increase in the release degree of the tunnel profile displacement, the isochromatic fringes obviously change (see
Figure 21). The range of "ellipsoidal" regions with different colours at the end of the bolt (cable) becomes larger, the colourless region around the anchor body gradually becomes coloured, and the striped zone extends from the excavation profile surface to the in-depth surrounding rock mass. Therefore, it is evident that the excavation unloading device developed for the large-scale photoelastic model test 


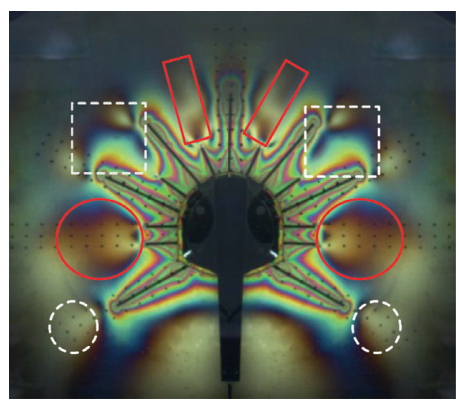

(a)

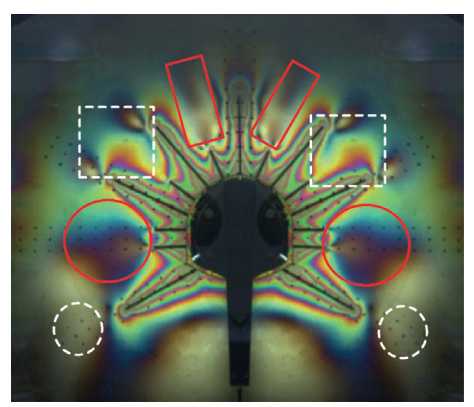

(b)

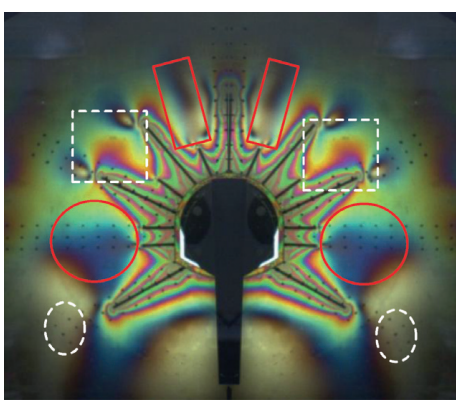

(c)

FIGURE 21: Bright-field isochromatic fringes under different excavation unloading conditions. (a) Displacement unreleased. (b) Displacement released once. (c) Displacement released twice (full release).

can effectively simulate the weakening process of the spatial constraint effect and the dynamic adjustment of stress and displacement in the tunnel structure during the tunnel excavation process.

\section{Conclusions}

(1) In this paper, the geo-stress loading device for the in situ geo-stress simulation for the photoelastic model test is studied, designed, processed, and assembled. The geo-stress loading device is designed as an integral loading part in the form of load sharing, in which the loading rod for the universal retaining force can realize stability and effective compensation for loading, which is an original design. Through theoretical analyses and numerical simulations, the strength of the pin shaft of the universal joint, the retaining force of the spring, and deformation of the reaction frame are analysed. The geo-stress loading device can simulate an in situ geo-stress environment, such as unidirectional loading, bidirectional equal pressure, bidirectional unequal pressure, and tridirectional unequal pressure, which promotes the application of large-scale photoelastic model tests in deep tunnels and other underground engineering fields.

(2) Based on the principle of the umbrella-shaped expansion and contraction mechanism, an excavation unloading device for the excavation profile in the large-scale photoelastic model test was developed, and the machining amount of the support block and displacement error of this device were analysed. The device can realize the simulation of various release degrees of tunnel profile displacement during the excavation process of deep tunnels and other underground projects and make it possible for photoelastic model tests to capture the stress characteristics and force transfer mechanism of the surrounding rock mass and supporting structure during the process of displacement adjustment after tunnel excavation. Therefore, the research ability and engineering applicability of the photoelastic model test is greatly improved.
(3) The verification tests for geo-stress loading and excavation unloading devices showed that the largescale geo-stress loading device of the large-scale photoelastic model test for the deep tunnel can reach the applied level of the designed uniform load. When applied to the photoelastic model test with a predetermined load, the geo-stress loading device still retained good load stability and high accuracy for load adjustment. The rotating hand-wheel of the excavation unloading device provided stable and firm support, and the overall excavation unloading action was flexible and easy to control. The combination of the geo-stress loading and excavation unloading devices is of great significance in studying the stress characteristics, force transfer process, and sharing mechanism of the surrounding rock mass and supporting structure considering the excavation effect in a real geo-stress environment with photoelastic model tests.

\section{Data Availability}

The data used to support the findings of this study are included and provided within the article.

\section{Conflicts of Interest}

The authors declare that there are no conflicts of interest regarding the publication of this study.

\section{Acknowledgments}

This work was supported by the National Natural Science Foundation of China (Grant nos. 51474097 and 51778215) and the China Postdoctoral Science Foundation funded project (Grant no. 2018M631114).

\section{References}

[1] Q. Yin, J. Wu, C. Zhu, M. He, Q. Meng, and H. Jing, "Shear mechanical responses of sandstone exposed to high temperature under constant normal stiffness boundary conditions," Geomechanics and Geophysics for Geo-Energy and GeoResources, vol. 7, no. 2, pp. 1-17, 2021. 
[2] G. Feng, Y. Kang, X. Wang, Y. He, and X. Li, "Investigation on the failure characteristics and fracture classification of shale under Brazilian test conditions," Rock Mechanics and Rock Engineering, vol. 53, no. 7, pp. 3325-3340, 2020.

[3] C. Zhu, M. He, X. Zhang, Z. Tao, Q. Yin, and L. Li, "Nonlinear mechanical model of constant resistance and large deformation bolt and influence parameters analysis of constant resistance behaviour," Rock and Soil Mechanics, vol. 42, no. 7, pp. 1911-1924, 2021.

[4] L. Malmgren and E. Nordlund, "Interaction of shotcrete with rock and rock bolts-a numerical study," International Journal of Rock Mechanics and Mining Sciences, vol. 45, no. 4, pp. 538-553, 2008.

[5] M. He, H. Xie, S. Peng, and Y. D. Jiang, "Study on rock mechanics in deep mining engineering," Chinese Journal of Rock Mechanics and Engineering, vol. 45, no. 16, pp. 28032813, 2005.

[6] J. Fu, Q. Liu, Z. Qin et al., “Analytic prediction of the stress and displacement field of roadway wallrock based on viscoelastic theory," Metal Mine, vol. 2009, no. 4, pp. 87-90, 2009.

[7] M. Ghadimi, K. Shahriar, and H. Jalalifar, "Study of fully grouted rock bolt in tabas coal mine using numerical and instrumentation methods," Arabian Journal for Science and Engineering, vol. 41, no. 6, pp. 2305-2313, 2016.

[8] Q. Feng, B. Jiang, G. Wang, and C. Hu, "Analytical solution for a circular roadway considering the transient effect of excavation unloading," International Journal of Mining Science and Technology, vol. 26, no. 4, pp. 543-549, 2016.

[9] Y. Ju, Y. Wang, C. Su, D. Zhang, and Z. Ren, "Numerical analysis of the dynamic evolution of mining-induced stresses and fractures in multilayered rock strata using continuumbased discrete element methods," International Journal of Rock Mechanics and Mining Sciences, vol. 113, pp. 191-210, 2019.

[10] Q. Wang, Y. Wang, M. He et al., "Experimental research and application of automatically formed roadway without advance tunnelling," Tunnelling and Underground Space Technology, vol. 114, 2021.

[11] Z. Yang, Q. Guan, Q. Hu et al., “Analysis of roadway stability by strength reduction finite difference method based on flac3d," Industrial Construction, vol. 44, no. S1, pp. 821-824, 2014.

[12] S. C. Li, Q. Wang, H. Wang et al., "Model test study on surrounding rock deformation and failure mechanisms of deep roadways with thick top coal," Tunnelling and Underground Space Technology, vol. 47, pp. 52-63, 2015.

[13] Y. Lu and C. Liu, "Similarity simulation of bolt support in a coal roadway in a tectonic stress field," Mining Science and Technology, vol. 20, no. 5, pp. 718-722, 2010.

[14] H. Wang, Q. Wang, H. Li, W. Li, and D. Zhang, "Development of flexible uniform pressure loading system for model test and its application," Rock and Soil Mechanics, vol. 23, no. 7, pp. 1945-1950, 2012.

[15] Y. Ma, Q. Zeng, and X. Zhang, "Photoelastic experimental modelling of evolution of cenozoic tectonic stress field and analysis of petroleum geological condition in huanghua depresson," Journal of Geomechanics, vol. 8, no. 3, pp. 219228, 2002.

[16] B. Li and G. Yang, "On the application of photoelasticitydigital speckle correlation hybrid method in separation of main stress photoelastic fringes," Journal of Experimental Mechanics, vol. 28, no. 2, pp. 180-186, 2013.

[17] V. F. Trumbachev and G. A. Katkov, "Experimental application of photoelastic coatings for the determination of stresses and loads on the supports of mining excavations," International Journal of Rock Mechanics and Mining Science \& Geomechanics Abstracts, vol. 3, no. 4, pp. 337-347, 1966.

[18] T. Zhou, G. Zhou, B. Liao et al., "Three-dimensional photoelasticity model test of inclined shaft on stress distribution in thick sand soil layer," Journal of China Coal Society, vol. 42, no. 8, pp. 1979-1986, 2017.

[19] M. Wang, Z. M. Zhu, and J. H. Liu, "The photoelastic analysis of stress intensity factor for cracks around a tunnel," Applied Mechanics and Materials, vol. 142, no. 3, pp. 197-200, 2011.

[20] J. Gao and Z. Dun, "Investigation of rock-bolting by photoelastic experiments," Journal of China Coal Society, vol. 1989, no. 4, pp. 39-44, 1989.

[21] J. Gao and Z. Dun, "Photoelastic experimental study on the stress state of full-length bonded bolt body," Zhongzhou Coal, vol. 1987, no. 5, pp. 14-16, 1987.

[22] B. Cheng, Y. Sun, M. Xu et al., "Photoelastic experiment and Simulation for pressure relief at deep mine," Industrial Minerals \& Processing, vol. 2011, no. 6, pp. 20-23, 2011.

[23] S. Hu, Y. Ye, N. Hu et al., "Study on shear stress distribution characteristics at the top of contact roadway with different contact angles," Metal Mine, vol. 2018, no. 8, pp. 33-39, 2018.

[24] J. Wang, X. Han, and W. Pang, "Photelastic experimental study on force chain structure and evolution in top coal and overlaying strata under fully mechanized top coal caving mining," Chinese Journal of Engineering, vol. 39, no. 1, pp. 13-22, 2017.

[25] Y. Wang, Simulation Contrast Study on the Underground Structural Design Parameters of Water-Sealed Liquefied Petroleum Gas Caverns, China University of Geosclences, Beijing, China, 2013.

[26] C. Zhang, X. Zhang, H. Li, and D. Zhang, "Model test on failure laws of ground with voids induced by shallow tunnelling," Chinese Journal of Geotechnical Engineering, vol. 38, no. 2, pp. 263-270, 2016.

[27] Q. Wang, M. He, S. Li et al., "Comparative study of model tests on automatically formed roadway and gob-side entry driving in deep coal mines," International Journal of Mining Science and Technology, vol. 31, no. 4, pp. 591-601, 2021.

[28] X. Liu, J. Luo, and J. Guo, Research on Mechanical Characteristics of Composite Support System in Deep Roadway, China University of Ming and Technology Press, Xuzhou, China, 2018.

[29] Q. Liu, W. Gao, and L. Yuan, Stability Control Theory, Support Technology and Application of Deep Rock Roadway in Coal Mine, Science Press, Beijing, China, 2010. 